coronary artery and its relatively rapid growth as a fibroma. The growth period might have been even less than 34 months because no imaging was undertaken during the postoperative period after aortic valve replacement.

The preoperative CT scan and angiogram were of great help in planning complete resection of the tumor, avoiding injury to the coronary arteries and the left ITA under reoperation conditions and without extracorporeal circulation.

Because local recurrence is possible in benign, as well as malignant, forms of SFT resected incompletely, radical resection should be strived for in all patients.

\section{References}

1. De Perrot M, Fischer S, Bründler MA, Sekine Y, Keshavjee S. Solitary fibrous tumors of the pleura. Ann Thorac Surg. 2002;74:285-93.

2. El-Naggar AK, Ro JY, Ayala AG, Ward R, Ordóñez NG. Localized fibrous tumor of the serosal cavities. Immunohistochemical, electron-microscopic, and flow-cytometric DNA study. Am J Clin Pathol. 1989;92:561-5.

3. Val-Bernal JF, Figols J, Gómez-Román JJ. Incidental localized (solitary) epithelial mesothelioma of the pericardium: case report and literature review. Cardiovasc Pathol. 2002;11:181-5.

4. Flemming P, Maschek H, Werner M, Kreft A, Graeter T, Georgii A. Solitary fibrous tumor of the epicardium. Pathologe. 1996;17:139-44.

5. Andreani SM, Tavecchio L, Giardini R, Bedini AV. Extrapericardial solitary fibrous tumour of the pericardium. Eur J Cardiothorac Surg. 1998; 14:98-100

\title{
A word of caution: Cerebral air emboli caused by tubing elastic recoil while performing low-flow antegrade cerebral perfusion in a low-birth-weight neonate
}

\author{
Georgy Frenkel, MD, ${ }^{\mathrm{a}}$ Einat Birk, MD, ${ }_{\mathrm{b}}$ Bernardo Vidne, MD, ${ }^{\mathrm{a}}$ Golan Shukrun, PCP, ${ }^{\mathrm{a}}$ Oren Bachar, PCP, ${ }^{\mathrm{a}}$ \\ Yakov Katz, MD, ${ }^{\mathrm{c}}$ and Gabriel Amir, MD, PhD, ${ }^{\mathrm{a}}$ Petach Tikva, Israel
}

With continuous improvement of cardiac surgical techniques, we are currently able to perform complex congenital heart surgery, even in small neonates. ${ }^{1,2}$ Some of the complex operations of the aortic arch involve hypothermia and either deep hypothermic circulatory arrest or antegrade cerebral perfusion (ACP). Traditionally, deep hypothermic circulatory arrest has been used when neonatal arch surgery was performed. Recently, the use of ACP has been advocated as a means of brain protection. ${ }^{3}$ Two basic techniques for ACP have been used: either suturing a polytetrafluoroethylene shunt (Gore-Tex shunt; W. L. Gore \& Associates, Inc, Flagstaff, Ariz) to the innominate artery or direct cannulation of either the ascending aorta or the innominate artery. We herein report a case in which ACP was used in a 2-kg neonate. Once ACP was initiated, air bubbles were seen in the arterial cannula, rising toward the pump. The air bubbles

\footnotetext{
From the Division of Pediatric Heart Surgery, ${ }^{\mathrm{a}}$ Department of Pediatric Cardiology, and Pediatric Anesthesia, ${ }^{\mathrm{c}}$ Schneider Children's Medical Center of Israel, Petach Tikva, Israel.

Disclosures: None.

Received for publication March 27, 2008; revisions received Aug 17, 2008; accepted for publication Aug 27, 2008; available ahead of print Jan 19, 2009.

Address for reprints: Gabriel Amir, MD, PhD, Division of Pediatric Heart Surgery, Schneider Children's Medical Center of Israel, 14 Kaplan St, Petach Tikva 49202, Israel (E-mail: gabrielA@clalit.org.il).

J Thorac Cardiovasc Surg 2010;139:e25-6 0022-5223/\$36.00

Crown Copyright (C) 2010 Published by Elsevier Inc. on behalf of The American Association for Thoracic Surgery

doi:10.1016/j.jtcvs.2008.08.037
}

were caused by a tubing recoil phenomenon apparent only when low pump flows were used.

\section{CLINICAL SUMMARY}

A premature 32-week-old neonate was given a diagnosis of severe coarctation and posterior malalignment ventricular septal defect. Arch anatomy consisted of a left aortic arch with an aberrant right subclavian artery. The operation was performed through a median sternotomy. After subtotal thymectomy and opening of the pericardium, cardiopulmonary bypass (CPB) was initiated through a 3.5 -mm polytetrafluoroethylene shunt sutured to the right carotid artery, the aortic cannula was connected to the shunt, and venous return was obtained through bicaval venous cannulation. Pump occlusion was checked before the initiation of CPB. CPB was initiated, and the patient was cooled to $18^{\circ} \mathrm{C}$. the aortic arch was dissected, and the anatomy was evaluated; the ductus arteriosum was ligated and divided. Snares were placed around the left and right carotid arteries and the left subclavian artery. The right subclavian artery was incorporated in the distal clamp. Once the temperature reached $18^{\circ} \mathrm{C}$, the brachiocephalic vessels were clamped, and ACP was initiated $\left(30 \mathrm{~mL} \cdot \mathrm{kg}^{-1} \cdot \mathrm{min}^{-1}, 60 \mathrm{~mL} / \mathrm{min}\right)$. Arch reconstruction was initiated. On initiation of ACP, air bubbles were seen in the arterial cannula flowing toward the pump. Perfusion was immediately stopped, and protective measures were undertaken. The patient was positioned in a deep Trendelenburg position, and retrograde brain perfusion was initiated through the superior vena cava. Aortic arch 
reconstruction was completed, and full CPB was resumed. Throughout the operation, flows and lactate levels were adequate. Ventricular septal defect closure was completed through the right atrium. The patient was rewarmed and easily weaned from CPB.

Once the operation was finished, we rechecked the occlusion, and it was found to be adequate. We evaluated the amount of flow coming from the arterial cannula into a sterile cup. We started at flows of $120 \mathrm{~mL} / \mathrm{min}$. The blood flow coming from the cannula was phasic but continuous. Once flows decreased to less than $70 \mathrm{~mL}$, the phasic flow recoiled into the aortic cannula, filling it with air. It seems that when low pump flows $(<70 \mathrm{~mL})$ are used, this recoil phenomenon can suck air through small suture holes made in the polytetrafluoroethylene shunt.

Once in the intensive care unit, the patient underwent head ultrasonography that demonstrated a mild degree of edema, followed by magnetic resonance imaging, the results of which were read as normal. The patient subsequently woke up and seemed neurologically intact, eventually making a full recovery.

\section{DISCUSSION}

Congenital cardiac surgery performed on low-birthweight neonates is challenging technically, and there is a small margin of error. Stretching the limits sometimes uncovers technical pitfalls. A similar phenomenon of air embolization through polytetrafluoroethylene needle holes has been attributed to the withdrawal of samples from the arterial circuit during low-flow conditions or to the presence of an open arterial-venous loop in the circulation for blood sampling. Our circuit has a unidirectional valve that prevents air embolization during either active or passive sample withdrawal under low-flow conditions. It seems that a roller pump is limited in administering extremely low flows. In our case the administration of $60 \mathrm{~mL} / \mathrm{min}$ through a polytetrafluoroethylene shunt caused air to be sucked through the needle holes. The roller pump periodically compresses the pump tubing, squeezing the fluid through. Subsequently, the tube expands, creating a vacuum both backward and forward. When the flow is high, this "recoil" is overcome by the inertia of the fluid in the tubing; nevertheless, if pump flow is too low, air can be sucked in through areas of minimal resistance, such as needle holes or loose snares. Increasing the occlusion on the tubing minimized the recoil phenomenon and stopped the sucking of air at $60 \mathrm{~mL} / \mathrm{min}$.

In conclusion, care should be taken when performing ACP at flows of less than $70 \mathrm{~mL} / \mathrm{min}$. If possible, direct cannulation might be beneficial, and a tighter occlusion of the tubing should be practiced. If air embolism is suspected, protective measures should be exercised. If possible, brain-monitoring technologies, such as near-infrared spectroscopy, should be applied for the detection of unexpected brain insults.

\section{References}

1. Curzon CL, Milford-Beland S, Li JS, O'Brien SM, Jacobs JP, Jacobs ML, et al. Cardiac surgery in infants with low birth weight is associated with increased mortality: analysis of the Society of Thoracic Surgeons Congenital Heart Database. J Thorac Cardiovasc Surg. 2008;135:546-51.

2. Netz BC, Hoffmeier A, Krasemann T, Zahn P, Scheld HH. Low weight in congenital heart surgery: is it the right way? Thorac Cardiovasc Surg. 2005;53:330-3.

3. Williams GD, Ramamoorthy C. Brain monitoring and protection during pediatric cardiac surgery. Semin Cardiothorac Vasc Anesth. 2007;11:23-33. 